\title{
Xiaocheng Gu (1930-2012)
}

Cell Research (2013) 23:167. doi:10.1038/cr.2013.18; published online 4 February 2013

Xiaocheng $\mathrm{Gu}$, a crystallographer and professor emeritus, in the College of Life Sciences, Peking University, died on November 3, 2012, from complications of kidney cancer. Professor Gu was born on February 13th, 1930 in Shanghai, China. Professor Gu attended Peking University, the Department of Plant Sciences, for her bachelor's degree (1948-1952). She obtained advanced training in protein crystallography in the Department of Chemistry, Peking University (1961-1964). Like most of the intellectuals in China during that period, Professor Gu's scientific career was interrupted by the "Cultural Revolution" from 1966 through 1976. From 1978 to 1984, Professor Gu was the Deputy Chairperson, Department of Biology, Peking University. In 1985, she became the Chairperson of the same department, a position that she served until 1992. In 1995, she became Professor Emeritus.

Professor Gu was a key contributor to the highly successful CUSBEA (China-US Biochemistry Examination and Application) program which produced a new generation of prominent Chinese biologists. China was essentially closed to the west after 1949. All of the college-level education stopped when the "Cultural Revolution" started in 1966. While China was trapped in chaos for the period of more than 10 years, a revolution in molecular biology was erupting in the west. Professor Gu was the chief coordinator of the CUSBEA program in China and worked tirelessly with the late Professor Ray Wu to establish this program in 1981. In the following eight years, the CUSBEA program successfully selected and sent

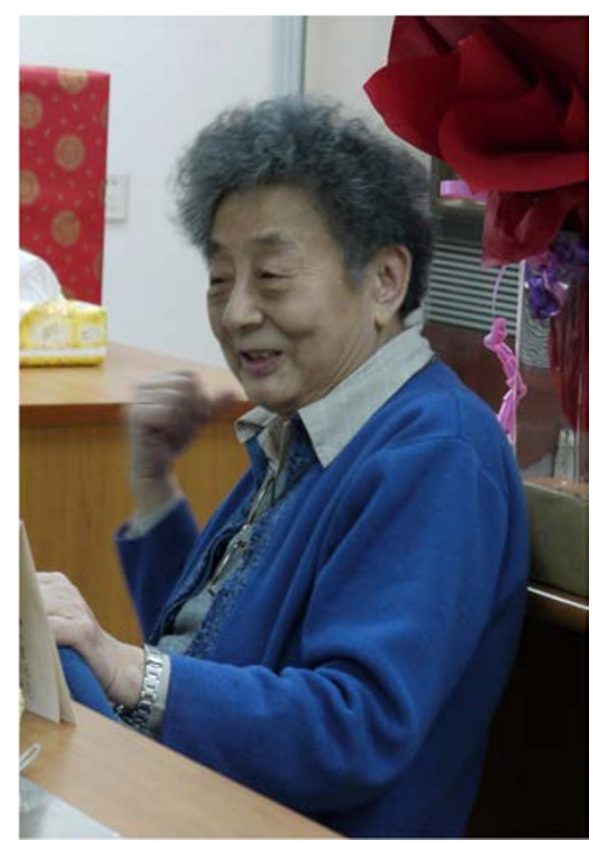

will dearly miss her. Professor Gu is survived by her husband, Dr. Rongye Cai, and her daughter, Ying Cai and son-in-law.

Jun-Ying Yuan ${ }^{1}$, Xiao-Hong Sun², Ming $\mathrm{Luo}^{3}$

${ }^{I}$ Harvard Medical School; ${ }^{2}$ Oklahoma Medical Research Foundation; ${ }^{3}$ University of Alabama E-mails: Junying_yuan@hms.harvard.edu; sunx@omrf.org; mingluo@uab.edu an elite group of Chinese college graduates to study molecular biology in the US. Professor Gu helped each student in the application to the Ph.D. programs. A decade later, she co-organized a series of scientific symposia that brought overseas young Chinese biologists, especially the CUSBEA graduates, in touch with universities and research institutes in China. Some of the attendees now have returned to China and established world-class laboratories that are conducting leading biological research. Many others have established long-term collaborations with colleagues in China. Her efforts helped to reduce the gap between biological research activities in China and the west.

Professor Gu was a beloved "mother" to all CUSBEA graduates, who are saddened by her premature passing and 